\title{
Thrombocytopenia and Altered Platelet Indices as Potential Marker in Complicated Malaria Caused by Plasmodium Vivax: Cross Sectional Descriptive Study
}

\author{
Bhavani K, Venkatraman J*, Roopa Urs A. N and Dhananjay S Kotasthane \\ Dept. of Pathology, Mahatma Gandhi Medical college and Research institute, Pondicherry, India
}

\begin{abstract}
Background: Malaria is a major health problem with increased morbidity and mortality. Plasmodium falciparum and Plasmodium vivax are endemic infections in India and constitutes about $77 \%$ of the total malaria cases in Southeast Asia, commonly associated with hematological abnormalities. Hematological abnormalities that are observed in patients with malaria includes anemia and thrombocytopenia. Thrombocytopenia frequently complicates malarial infections and is usually noted in Plasmodium falciparum. In the present study we have tried to evaluate prognostic implications of altered platelet indices and factors associated with outcome of severe and complicated P. vivax malaria.

Methods: This is cross sectional descriptive study of 60 patients with malaria caused by P. vivax who presented to Mahatma Gandhi medical college and research institute between june 2014 to April 2016. The smears positive for malaria exclusively caused by P.vivax infection were included in this study. Malaria was diagnosed by microscopic examination with both leishmain stained thin and giemsa stained thick smears. All blood cell counts were determined using automated equipment (ABX Pentra ES 60; Horiba) which provides MPV, PDW and PCT.

Result: Out of 60 patients in the present study $56.7 \%$ were males and $43.3 \%$ were females, age of the patient ranges from $17-48$ years with mean (SD) age of distribution were 32.10 (9.52). Complete blood count evaluation of all patients showed mean hemoglobin level of $9 \mathrm{~g} / \mathrm{dL}$. Mean hematocrit level of $26.68 \%(4.2 \%)$ and mean leukocyte count of $5866(1170)$ cells $/ \mathrm{mm} 3$. The mean platelet count was 95,247 cells/ $\mathrm{mm} 3$. The MPV was $9.6(0.96) \mu \mathrm{m}$, Mean PDW was $13.75 \%(0.89 \%)$ and mean PCT was $0.180 \%(0.033 \%)$

Conclusion: Our study concludes that history of fever associated with chills and rigor are sensitive indicator of malaria but lacks specificity. Platelet indices were altered during severe symptomatic malarial infection such as elevation of MPV and PDW with decreased PCT are the known potential risk factors associated with warning signs of acute malaria caused by plasmodium vivax. Even though these hematological parameters are useful predictors of acute malarial infection, identification of parasites and grading of parasitemia in peripheral smear were always gold standard for early treatment.
\end{abstract}

Keywords: Plasmodium Vivax, Malaria, Severe Thrombocytopenia.

\section{Introduction}

Malaria is a major health problem with increased morbidity and mortality. ${ }^{[1]}$ Plasmodium falciparum and Plasmodium vivax are endemic infections in India and constitutes about $77 \%$ of the total malaria cases in Southeast Asia, commonly associated with hematological abnormalities. ${ }^{[2,3]}$ According to World health organization, malaria is the second most fatal communicable disease and is a public health problem in 90 countries of the world.$^{[4]}$ Each year there are more than 250 million cases of malaria, killing 1 to 3 million people. ${ }^{[1,5]}$ Hematological abnormalities that are observed in patients with malaria includes anemia and thrombocytopenia. ${ }^{[5,6]}$ Thrombocytopenia frequently complicates malarial infections and is usually noted in Plasmodium falciparum. ${ }^{[6]}$ But it also frequently observed in vivax malaria but the exact mechanism has not been elucidated and bleeding episodes are also rare in these patients. ${ }^{[7,8,9]}$ In general, the underlying mechanisms of thrombocytopenia are found to be due to peripheral destruction, excessive sequestration of plateletsin spleen, excessive use of platelets associated with DIC, increased levels of cytokines, immunological destruction due to antiplatelet $\operatorname{IgG}$ and anti-oxidative mechanisms of thrombocytes were insufficient in malaria patients and caused oxidative stress. ${ }^{[1-15]}$ The oxidative damage of thrombocytes might be important in the etio-pathogenesis of thrombocytopenia occurring in malaria. ${ }^{[10,11,12]}$

In addition to reduction in number of platelets, functions of platelet is also compromised which is generally evident in platelet indices. ${ }^{[13]}$ Platelet also plays important role in inflammation and depending upon severity of bacterial infection changes in platelet count and indices also has been 
reported, further platelet activation also alters mean platelet volume (MPV) and platelet distribution width (PDW). ${ }^{[14-}$

17] Plateletcrit is also another marker for measurement of platelet biomass which combines mean platelet volume with absolute platelet count. MPV,PDW and PCT are considered as markers of platelet activation and altered in different clinical condition and they were also altered in malaria caused by vivax, however the relation between platelet indices and clinical outcome were controversial especially between altered PDW or PCT and severity of malaria caused by vivax..$^{[17,18]}$ In the present study we have tried to evaluate prognostic implications of altered platelet indices and factors associated with outcome of severe and complicated P. vivax malaria. ${ }^{[19,20]}$

\section{Materials and Methods}

This is cross sectional descriptive study of 60 patients with malaria caused by P. vivax who presented to Mahatma Gandhi medical college and research institute between june 2014 to April 2016. The smears positive for malaria exclusively caused by P.vivax infection were included in this study. Complete blood count and biochemical analysis was done for all the patients. Malaria was diagnosed by microscopic examination with both leishmain stained thin and giemsa stained thick smears. All blood cell counts were determined using automated equipment (ABX Pentra ES 60; Horiba) which provides MPV, PDW and PCT.

Severe and complicated malaria was defined by using WHO predictors ${ }^{[4,5,6]}$ or by using following haematological, biochemical and clinical parameters at the time of admission:

Body temperature $\geq 41^{\circ} \mathrm{C}$, dyspnoea, hypotension, serum creatinine level $>1.5 \mathrm{mg} / \mathrm{dL}$, hypoglycaemia, hyperbilirubinaemia, $\quad$ haemoglobin $<7 \quad \mathrm{~g} / \mathrm{dl}$, haematocrit $<20 \%$ and primary infection lasts for more than 3 days also consider potential risk factor.

The Mann- whitney non parametric test was used to analyse the association between platelet indices with warning signs of indicators of severe or complicated malaria caused by $P$. vivax. Spearman's correlation coefficients was calculated to evaluate the relationships between platelet indices and parasitaemia. Multiple logistic regression analysis was constructed with each parameter as a dependent variable to analyze the independence of the associations between various severity of malaria and platelet indices. The level of significance was $p<0.05$.

\section{Result}

Out of 60 patients in the present study $56.7 \%$ were males and $43.3 \%$ were females, age of the patient ranges from $17-48$ years with mean (SD) age of distribution were
32.10 (9.52). The duration between onset of symptoms and diagnosis of malaria ranges from one to thirteen days. At the time of diagnosis $31.67 \%$ of patients had body temperature more than $41^{\circ} \mathrm{C}$. Sixteen patients $(26.67 \%)$ had at least one warning sign of severe and complicated malaria including clinical and biochemical parameters. The mean parasitemia observed in sixty patients was 7397(SD 2285.82) parasites $/ \mathrm{mm}^{3}$. No patient had potential drug history which interferes with platelet indices.

Complete blood count evaluation of all patients showed mean hemoglobin level of $9 \mathrm{~g} / \mathrm{dL}$. Mean hematocrit level of $26.68 \%$ (4.2\%) and mean leukocyte count of 5866 (1170) cells $/ \mathrm{mm}^{3}$. The mean platelet count was $95,247 \mathrm{cells} / \mathrm{mm}^{3}$. The MPV was $9.6(0.96) \mu \mathrm{m}$, Mean PDW was $13.75 \%$ $(0.89 \%)$ and mean PCT was $0.180 \%(0.033 \%)$

\section{Discussion}

India is considered in control phase of malaria with annual parasitic incidence of 0.7-1.6 million in 2014. ${ }^{[4]}$ Many hematological parameters were useful in early diagnosis. In this study, specifically total leucocyte count and platelet counts were lower and significantly much lower in patients with warning signs and symptoms of complications as compared to the studies done by Kochar et al from northwestern India, Taylor et al northern-east papua and Saravu et al from Karnataka. ${ }^{[21,22,23]}$ Anemia has been documented in our study population and nutritional status may also be the attributive cause for it. However associated hemoglobinopathies were not excluded. Many studies also noted poor correlation between anemia and malaria. ${ }^{[24,25,26]}$ Studies from Delhi have reported $80.37 \%$ to $96 \%$ of P. vivax malarial infection with thrombocytopenia as compared to our study has showed $82-93.5 \% .^{[27,28]}$ Pathogenesis of thrombocytopenia in malaria is due to peripheral destruction, splenic pooling or consumption coagulopathy but mast et al study has suggested thrombocytopenia in early malaria associated with Gplb shedding in absence of platelet activation and coagulopathy and is not at all due to reduction in megakaryocytes in marrow which are usually normal. ${ }^{[29]}$ An inverse relationship was seen between parasite density and platelet counts and platelet counts returned to normal with treatment as similar to other studies. ${ }^{[30]}$ Platelet indices show increase in mean platelet volume and platelet distribution width as platelet count decreases due to platelet aggregation leads to platelet dysfunction ${ }^{[30]}$. Chandra et al study says that MPV increased because of peripheral destruction of platelets and MPV decreased in cases of bone marrow parasitemia (due to hypoproduction). ${ }^{[31]}$ However in this present study, MPV was increased in almost $90 \%$ of cases but bone marrow examination was done in few follow up cases with increased MPV to confirm marrow parasitaemia but all of 
Table 1: Comparision between platelet indices and indicators of severity in the patients with Plasmodium vivax malaria

\begin{tabular}{|c|c|c|c|c|c|c|c|}
\hline & & \multicolumn{2}{|c|}{ MPV } & \multicolumn{2}{|c|}{ PDW } & \multicolumn{2}{|c|}{ PCT } \\
\hline & & Mean & SD & Mean & SD & Mean & SD \\
\hline \multirow{3}{*}{ First_Infection } & Yes & 10.46 & 1.07 & 14.41 & 1.35 & 0.17 & 0.03 \\
\hline & No & 9.34 & 0.66 & 13.45 & 0.26 & 0.18 & 0.03 \\
\hline & $\mathrm{p}$-value & \multicolumn{2}{|c|}{0.000006880} & \multicolumn{2}{|c|}{0.000044049} & \multicolumn{2}{|c|}{0.168368355} \\
\hline \multirow{3}{*}{ time_Onset1 } & Yes & 9.67 & 0.97 & 13.84 & 1.01 & 0.18 & 0.03 \\
\hline & No & 9.78 & 0.95 & 13.48 & 0.28 & 0.19 & 0.04 \\
\hline & $\mathrm{p}$-value & \multicolumn{2}{|c|}{0.690476231} & \multicolumn{2}{|c|}{0.170173984} & \multicolumn{2}{|c|}{0.549631323} \\
\hline \multirow{3}{*}{ severity } & Yes & 10.71 & 0.99 & 14.68 & 1.31 & 0.18 & 0.03 \\
\hline & No & 9.33 & 0.63 & 13.42 & 0.26 & 0.18 & 0.03 \\
\hline & $p$-value & \multicolumn{2}{|c|}{0.000000032} & \multicolumn{2}{|c|}{0.000000090} & \multicolumn{2}{|c|}{0.953929067} \\
\hline
\end{tabular}

Table 2: Clinical and laboratory characteristics of patients with malaria caused by Plasmodium vivax

\begin{tabular}{|c|c|c|c|c|c|}
\hline Variable & & Frequency & Percent & Mean & SD \\
\hline \multirow[t]{3}{*}{ Age1 } & $<=20$ & 9 & 15 & \multirow{3}{*}{32.10} & \multirow{3}{*}{9.52} \\
\hline & $21-40$ & 39 & 65 & & \\
\hline & $>40$ & 12 & 20 & & \\
\hline \multirow[t]{2}{*}{ Sex } & Female & 26 & 43.3 & & \\
\hline & Male & 34 & 56.7 & & \\
\hline \multirow[t]{3}{*}{ No_of_Days1 } & 1 & 1 & 1.7 & \multirow{3}{*}{4.63} & \multirow{3}{*}{1.79} \\
\hline & $2-4$ & 18 & 30 & & \\
\hline & $>4$ & 41 & 68.3 & & \\
\hline \multirow[t]{2}{*}{ severity } & No & 44 & 73.3 & & \\
\hline & Yes & 16 & 26.7 & & \\
\hline Parasitaemia & & & & 7397.00 & 2285.83 \\
\hline
\end{tabular}

Table 3 : Multivariate logistic regression analysis of the associations between platelet indices, demographic variables, and severity indicators

\begin{tabular}{|c|c|c|c|}
\hline Variables & Odds Ratio & $95 \%$ of Clearance & $P$ value \\
\hline $\begin{array}{l}\text { MPV } \\
\text { i.First time infection } \\
\text { ii.Recurrent infection with severity }\end{array}$ & $\begin{array}{l}3.42 \\
6.80\end{array}$ & $\begin{array}{c}1.46-8.38 \\
1.03-45.46\end{array}$ & $\begin{array}{l}0028 \\
0.046\end{array}$ \\
\hline $\begin{array}{l}\text { PDW } \\
\text { i.Recurrent Malarial infection } \\
\text { ii.Presence of complicated signs of severity }\end{array}$ & $\begin{array}{l}0.63 \\
5.83\end{array}$ & $\begin{array}{c}0.77-0.93 \\
2.20-41.36\end{array}$ & $\begin{array}{l}0.002 \\
0.017\end{array}$ \\
\hline
\end{tabular}

Table 4 : Comparison of variation in platelet indices in post treatment Plasmodium vivax infected patients

\begin{tabular}{|l|c|c|}
\hline Parameters & $\begin{array}{c}\text { Mean } \\
\text { (SD) of }(\mathbf{n = 4 1 )}\end{array}$ \\
\hline TLC & $6.27 \times 10^{9} / \mathrm{L}(1.08)$ & $4.13 \times 10^{9} / \mathrm{L}(0.46)$ \\
\hline PC & $2.73 \times 10^{9} / \mathrm{L}(1.01)$ & $1.23 \times 10^{9} / \mathrm{L}(0.83)$ \\
\hline PDW & $23.53(1.31)$ & $13.84(1.07)$ \\
\hline MPV & $13.77(0.66)$ & $9.14(0.33)$ \\
\hline PCT & $0.18(0.03)$ & $0.19(0.14)$ \\
\hline
\end{tabular}




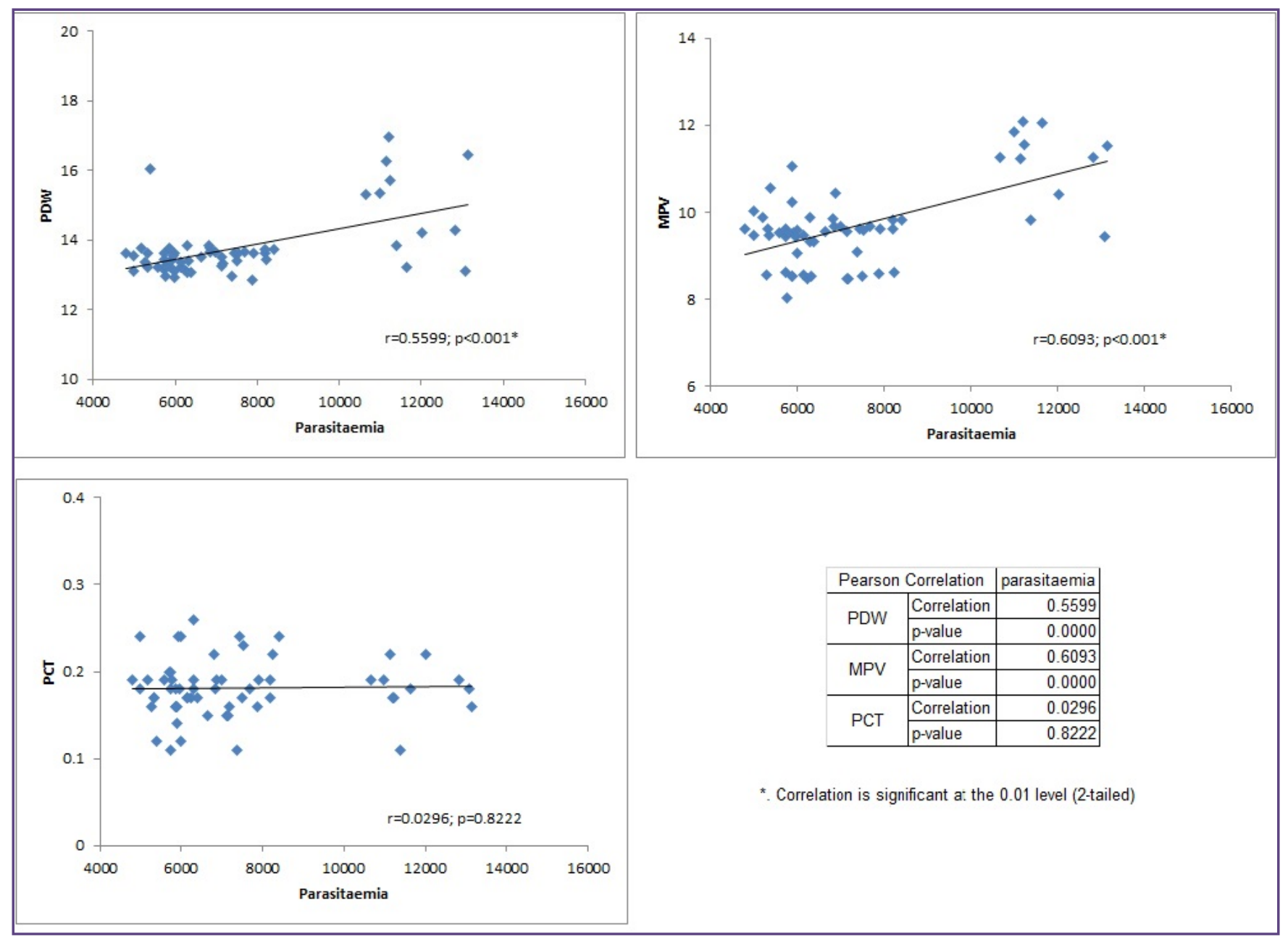

Fig. 1: Relationships between parasitic density and other variables in the patients with malaria caused by Plasmodium vivax.

them showed normal marrow poiesis and chronic ITP also ruled out.

One study has mentioned MPV in malaria should be considered as predictor of acute infection by P. vivax. ${ }^{[32]}$ Sushma et al study shows thrombocytopenia associated with increase in mean platelet volume and leucopenia were considered sensitive indicator for plasmodium vivax infection. ${ }^{[31]}$

PCT was low in this study, since PCT is measure of platelet biomass (which is due to concominant thrombocytopenia associated with P.vivax). PCT has negative correlation with level of parasitemia as observed in other studies. ${ }^{[33]}$

Change in platelet indices also influenced by warning signs of severe acute malaria such as longer duration of illness, hematological and biochemical parameters. ${ }^{[34]}$ These changes are mainly due to increased giant platelets which are metabolically and enzymatically more active and involves in inflammatory process. ${ }^{[35]}$ Initially in severe cases of malaria platelet shows hyperactivity followed by hypoactivity. Hyperactivity is due to various aggregating agents like immune complexes, surface contact of platelet membrane to parasitized RBC's and damage to endothelial cells which cause lyses of platelet inside the vessel and release its content which can cause even disseminated intravascular coagulation. Platelet distribution width was also increased due to variation in size of platelets (giant platelets) and also due to platelet aggregation. ${ }^{[29,34,35]}$

Post treatment follow up was done in 47 cases out of which 41 patient showed almost normal to mild leucocytosis and platelet also returns to near normal MPV and PDW were also normal in range but Plateletcrit was not showed much difference from previous value. This suggested that malaria was the most likely cause which alters the studied platelet parameters. $^{[33]}$

\section{Conclusion}

Our study concludes that history of fever associated with chills and rigor are sensitive indicator of malaria but 
lacks specificity. Hence thrombocytopenia $\left(<150 \times 10^{9} / 1\right)$ and leucopenia $\left(<4 \times 10^{9} / 1\right)$ used as probable indicator for malarial infection. Platelet indices were altered during severe symptomatic malarial infection such as elevation of MPV and PDW with decreased PCT are the known potential risk factors associated with warning signs of acute malaria caused by plasmodium vivax. Even though these hematological parameters are useful predictors of acute malarial infection, identification of parasites and grading of parasitemia in peripheral smear were always gold standard for early treatment.

\section{Acknowledgements}

Authors sincerely thank Dr Koteeswaran G, Professor, Dept of Pathology, Mahatma Gandhi medical college and research institute, Puducherry for her constant support. Authors also acknowledge the immense help received from the scholars who articles are cited and included in references of this manuscript.

\section{Reference}

1. Makkar, RPS, Mukhopadhyay S, Monga A, Gupta AK. Plasmodium Vivax Malaria Presenting With Severe Thrombocytopenia. The Brazilian Journal of Infectious Diseases 2002; 6 (5):263-265.

2. McNeeley DF, Chu A, Lowe S, et al. Malaria surveillance in New York City, 1991-1996. Int J Infect Dis. 1998;2:132-6.

3. Khan SJ, Khan FR, Usman M, Zahid S. Malaria can lead to Thrombocytopenia. Rawal MedJ 2008; 33: 183-55.

4. World Malaria Report 2009. WHO (cited on 2011, September 12). Available at: http://www.who.int/malaria/ world_malaria_report_2009/en/index.html. Last accessed on January, 2013.

5. Rodríguez-Morales AJ, Sánchez E, Vargas M, Piccolo C, Colina R, Arria M. Anemia and thrombocytopenia in children with Plasmodium vivax malaria. J Trop Pediatr. 2006;12:49-51. doi: 10.1093/tropej/fmi069

6. Patel U, Gandhi G, Friedman S, Niranjan S. Thrombocytopenia in Malaria. Journal of the national medical association 2004; 96 (9): 1212-1214.

7. Rizvi I, Tripathi DK, Chughtai AM, Beg M, Zaman S, Zaidi N. Complications associated with Plasmodium vivax malaria: a retrospective study from a tertiary care hospital based in western Uttar Pradesh, India. Ann Afr Med. 2013; 12:155-159. doi: 10.4103/1596-3519.117624. doi:10.4103/1596-3519.117624.

8. Jadhav UM, Patkar VS, Kadam NN .Thrombocyto-penia in Malaria - Correlation with Type and Severity of Malaria. JAPI 2004; 52: 615-618.

9. Gupta NK, Bansal SB, Jain UC, Sahare K. Study of thrombocytopenia in patients of malaria. Trop Parasitol. 2013;12:58-61. doi: 10.4103/2229-5070.113914. doi:10.4103/2229-5070.113914
10. Fajardo L.F., Tallent C. Malarial parasites within human platelets. JAMA 1974;229:1205.

11. Katira B, Shah I Thrombocytopenia in Plasmodium vivax infected children, J Vect j,Borne Dis 43, September 2006, pp. 147-9.

12. Erel O., Vural H., Aksoy N., et al. Oxidative stress of platelets andThrombocytopenia in patients with vivax malaria.Clin Biochem 2001; 34(4):341- 4.

13. Greisenegger S, Endler $\mathrm{G}$, Hsieh $\mathrm{K}$, Tentschert $\mathrm{S}$, Mannhalter C, Lalouschek W. Is elevated mean platelet volume associated with a worse outcome in patients with acute ischemic cerebrovascular events? Stroke. 2004;12:1688-1691.

14. Mirsaeidi M, Peyrani P, Aliberti S, Filardo G, Bordon J, Blasi F, Ramirez JA. Thrombocytopenia and thrombocytosis at time of hospitalization predict mortality in patients with community-acquired pneumonia. Chest. 2010;12:416-420.

15. Boos CJ, Beevers GD, Lip GY. Assessment of platelet activation indices using the ADVIATM 120 amongst "highrisk" patients with hypertension. Ann Med. 2007;12:72-78. doi: 10.1080/07853890601040063.

16. Jackson SR, Carter JM. Platelet volume: laboratory measurement and clinical application. Blood Rev. 1993;12:104-113. doi: 10.1016/S0268-960X(05)80020-7.

17. Becchi C, Al Malyan M, Fabbri LP, Marsili M, Boddi V, Boncinelli S. Mean platelet volume trend in sepsis: is it a useful parameter? Minerva Anestesiol. 2006;12:749-756.

18. Gasparyan AY, Ayvazyan L, Mikhailidis DP, Kitas GD. Mean platelet volume: a link between thrombosis and inflammation? Curr Pharm Des. 2011;12:47-58. doi: 10.2174/138161211795049804.

19. Lancé MD, Sloep M, Henskens YMC, Marcus MAE. Mean platelet volume as a diagnostic marker for cardiovascular disease: drawbacks of preanalytical conditions and measuring techniques. Clin Appl Thromb Hemost. 2012;12:561-568. doi: $10.1177 / 1076029612458147$.

20. Ladhani S, Lowe B, Cole AO, Kowuondo K, Newton CRJC. Changes in white blood cells and platelets in children with falciparum malaria: relationship to disease outcome. Br J Haematol. 2002;12:839-847. doi: 10.1046/j.13652141.2002.03904.x.

21. Kochar DK, Das A, Kochar A, Middha S, Acharya J, Tanwar GS, Gupta A,Pakalapati D, Garg S, Saxena V, Subudhi AK, Boopathi PA, Sirohi P, Kochar SK. Thrombocytopenia in Plasmodium falciparum, Plasmodium vivax and mixed infection malaria: a study from Bikaner (Northwestern India). Platelets 2010; 21: 623-627.

22. Taylor WR, Widjaja H, Basri H, Ohrt C, Taufik T, Tjitra E, Baso S, Fryauff D, Hoffman SL, Richie TL. Changes in the total leukocyte and platelet counts in Papuan and non Papuan adults from northeast Papua infected with acute Plasmodium vivax or uncomplicated Plasmodium falciparum malaria. Malar J 2008; 7:259. 
23. Saravu K, Docherla M, Vasudev A, Shastry BA. Thrombocytopenia in vivax and falciparum malaria: an observational study of 131 patients in Karnataka, India. Ann Trop Med Parasitol 2011; 105:593- 598.

24. Erhart Laura M,Yingyuen Kritsanai,Chuanak Niphon. Hematologic and clinical indices of malaria in a semiimmune population of western Thailand.Am. J. Trop. Med. Hyg. 2004;70(1): 8-14.

25. Maina Robert N, Walsh Douglas, Gaddy Charla. Impact of Plasmodium falciparum infection on haematological parameters in children living in Wester Kenya.Malaria Journal 2010; 9(Suppl 3):S4(1-11).

26. Richards MW, Behrens RH, Doherty JF. Short report: Hematologic changes in acute, imported Plasmodium falciparum malaria. Am. J. Trop. Med. Hyg.1998; 59(6): 859.

27. SharmaA, Khanduri U. How benign is benign tertian malaria? JVector Borne Dis 2009; 46: 141-144. PMid:18647661.

28. Singh H, Parakh A, Basu S, Rath B. Plasmodium vivax malaria : is it actually benign? J Infect Public Health 2011; 4: 91-95.

29. De Mast Q, de Groot PG, van Heerde WL, Roestenberg $\mathrm{M}$, van Velzen JF, Verbruggen B, Roest M, McCall M, Nieman AE, Westendorp J, Syafruddin D, Fijnheer R, van
Dongen-Lases EC, Sauerwein RW, van der Ven AJ. (2010). Thrombocytopenia in early malaria is associated with GP1b shedding in absence of systemic platelet activation and consumptive coagulopathy.Br J Haematol. 151: 495-503.

30. Sushma N, Reddy MM, Vijayashree R, Padmavathy F, Begum R, Arudra P Haematological Parameters Including Platelet Indices in Vivax and Falciparum Malaria. Chettinad Health City Medical Journal 2014; 3(3): 95 - 100.

31. Chandra H, Chandra S, Rawat A, Verma SK. Role of mean platelet volume as discriminating guide for bone marrow disease in patients with thrombocytopenia. Int J Lab Hematol 2010; 32: 498- 505.

32. Chandra S, Chandra H. Role of haematological parameters as an indicator of acute malarial infection in Uttarakhand state of India. Mediterr J Hematol Infect Dis. 2013;12:e2013009.

33. Leal-Santos Fábio, Silva Soraya BR, Crepaldi Natasha P. Altered platelet indices as potential markers of severe and complicated malaria caused by Plasmodium vivax: a crosssectional descriptive study.Malaria Journal 2013; 12:462.

34. Jadhav UM, Patkar VS, Kadam NN. Thrombocytopenia in Malaria - Correlation with Type and Severity of Malaria. JAPI, Aug 2004; Vol. 52:615-618.

35. Bashawri Layla AM, Mandil Ahmed A, Bahnassy Ahmed A, Ahmed Mirghani A. Malaria: Hematological aspects. Annals of Saudi Medicine. 1979; 22(5)-6 ;54:961 76.

*Corresponding author:

Dr Venkatraman J, Assistant Professor, Dept. of Pathology, ahatma Gandhi Medical college and Research institute, Pondicherry. India

Phone: +91 9894460460

Email: vforvenkat2005@yahoo.co.in

Date of Submission : 19.12.2016

Date of Acceptance : 01.03.2017

Financial or other Competing Interests: None.

Date of Publication : 05.06.2017 